\title{
PRODUÇÃO ACADÊMICA
}


AUTOR: João Alfredo Dal Bello

ORIENTADORA: Profa. Dra. Ruth Cerqueira de Oliveira Röhl

INSTITUIÇÃO: Universidade de São Paulo

TÍTULO: "Drama histórico: leitura metateatral de Brecht e Dorst"

DATA DA DEFESA: 29 de setembro de 1997

BANCA EXAMINADORA: Profa. Dra. Ruth Cerqueira de Oliveira Röhl (USP)

Profa. Dra. Ana Maria Burmester (UFPR)

Profa. Dra. Heidnun Brückner (GOETHE-INSTTTUT MÜNCHEN,

Alcmanha)

Profa. Dra. Renata Pallottini (USP)

Profa. Dra. Eloá Di Pierro Heise (USP)

QUALIFICAÇÃO: Doutor

\section{RESUMO}

O problema da escrita literária e a escrita da história apresenta-se para debate, em todas as épocas, e sempre volta a lançar questões que lhe são inerentes: como historiografia e criação literária se enfrentam em relação ao objeto histórico, qual a identidade de cada discurso e quais suas singularidades. Esta tese particulariza a relação dentro das fronteiras do chamado drama histórico. São enfocados dois dramaturgos alemães, em cuja obra a referência histórica é constante: Bertold Brecht e Tankred Dorst. $O$ interesse reside na indagação das similaridades e divergências na produção para o palco e na reflexão sobre a prática teatral. É, portanto, um trabalho de natureza contrastiva. Para embasar questões atinentes à estética, analisa-se uma obra de cada um deles pelo prisma da parábola, que responde por considerável parte de scus textos cênicos; duas outras são apostas pela ótica do drama histórico, vertente fértil na dramaturgia alemã, mas não isenta de controvertidas abordagens teóricas. Consulta-se, por isso, as distintas acep̧̧ões de drama histórico. Um grupo expressivo é configurado por pertinaz insistência na dicotomia verdadeiro-falso; outro, diametralmente oposto, acata que esse construto dramatúrgico apenas pode refletir o modo como o material histórico foi apropriado. No intuito de alcançar uma visão da forma dramática em Brecht e Dorst, é adotada a teoria do metateatro. Com tais procedimentos, busca-se estabelecer paralelos entre os autores estudados para dar conta de três aspectos da concepção e formulação de suas poéticas: a relação entre ficção e elementos historiográficos, a intenção da representação e a relação do espectador com o jogo. 
AUTOR: Mauricio Mendonça Cardozo

ORIENTADOR: Prof. Dr. João Azenha Jr.

INSTITUIÇĀO: Universidade de São Paulo

TÍTULO: "Quatro metáforas e uma tarefa: leitura da concepção benjaminiana de tradução à luz de sua natureza metafórica"

DATA DA DEFESA: 11 de agosto de 1999

BANCA EXAMINADORA: Prof. Dr. João Azenha Jr. (USP)

Profa. Dra. Irene T. Aron (USP)

Prof. Dr. Paulo Ottoni (UNICAMP)

QUALIFICAÇÃO: Mestre

\section{RESUMO}

No texto "A tarefa do tradutor", Walter Benjamin elabora a sua concepção de tradução. Para tanto, um dos principais instrumentos a que recorre é a metáfora. Ao fazer uso dessa figura de linguagem, o autor torna possível o tratamento concreto do que há de concreto na atividade tradutória e o tratamento abstrato do que há de abstrato nesse fenômeno. Ao proceder desse modo, além de refletir sobre a questão da tradução, acaba sugerindo, como opção às abordagens que se apóiam num modelo de tradução centrado no sentido, uma abordagem alternativa, cujo maior mérito é abordar o fenômeno da tradução como um todo, sem recortes. Propomos aqui uma leitura de "A tarefa do tradutor" à luz de quatro metáforas centrais a esse texto, com vistas à comprovação do uso destas enquanto instrumento eficiente na abordagem da tradução. 
AUTORA: Vera Lúcia da Rocha Maquêa

ORIENTADORA: Profa. Dra. Marta Morais da Costa

INSTITUIÇĀO: Universidade Federal do Paraná

TÍTULO: "O vampiro habita a linguagem: a narrativa de Dalton Trevisan"

DATA DE DEFESA: 29 de janeiro de 1999

BANCA EXAMINADORA: Profa. Dra. Marta Morais da Costa (UFPR)

Prof. Dr. Carlos Eduardo Ornelas Berriel (UNICAMP)

Prof. Dr. Édison José da Costa (UFPR)

QUALIFICAÇÃO: Mestre

\section{RESUMO}

A presente dissertação discute o sentido do vampiro na ficção de Dalton Trevisan, como o motivo gerador da narrativa. O caminho da investigação é trilhado desde os primeiros momentos sinais do vampiro na obra, passando pela sua configuração e maturação, até o momento em que ele se desloca, provocando no discurso similar deslocamento. Esse deslocamento discursivo passa pela mudança do vampiro, que ao abdicar de ser diretamente tematizado se instala subrepticiamente no procedimento de construção da narrativa, inaugurando a palavra poética na obra do autor. O percurso do vampiro é explorado a partir de suas marcas no texto como acontecimento de mudança que se dá na base da repetição. A insistência no mesmo material cria na narrativa de Dalton Trevisan um aparente paradoxo: só é possível dizer o novo dizendo "de novo". A linguagem vampirizada vai expressando, cada vez de maneira mais contundente, uma concepção de literatura respaldada pelo vigor e concentração de sentido da palavra. Assim, o silêncio vai aos poucos presentificando o sentido de uma hipersignificação, em que o próprio silêncio entra a repetir-se no encantamento e no prazer de narrar, estranha $\mathfrak{e}$ indefinidamente, a possibilidade de reedição da vida. 
AUTORA: Priscila Célia Giacomassi

ORIENTADORA: Profa. Dra. Regina Maria Przybycien

INSTITUIÇÃO: Universidade Federal do Paraná

TÍTULO: "The theme of heroism in modern parahistorical drama"

DATA DE DEFESA: 9 de fevereiro de 1999

BANCA EXAMINADORA: Profa. Dra. Regina Maria Przybycien (UFPR)

Profa. Dra. Maria Silvia Betti (USP)

Prof. Dr. João Alfredo Dal Bello (UFPR)

QUALIFICAÇÃo: Mestre

\section{RESUMO}

O objetivo desta tese é analisar de que maneira o tema do heroísmo é apresentado em quatro peças teatrais parahistóricas modernas. Estas peças são: The crucible de Arthur Miller, A man for all seasons de Robert Bolt, Saint Joan de Bernard Shaw e Life of Galileo de Bertold Brecht. O termo "parahistóricas" se deve à apropriação de heróis históricos (John Proctor, Thomas More, Joan D'Arc e Galileo Galilei) por estes dramaturgos. A recriação dramática destes personagens reflete uma busca do sentido do heroísmo no mundo atual. As peças também denunciam o autoritarismo, especialmente no que diz respeito a sua interferência na consciência individual. Para se entender o papel do herói nas peças, uma discussão a respeito das principais características desta figura intrigante é necessária. Esta discussão é feita no primeiro capítulo, no qual o papel e influência do herói são apresentados em alguns relevantes campos de conhecimento: mitologia, psicologia, história, religião e literatura. $\mathrm{O}$ mesmo capítulo tece considerações sobre as adversidades que o herói tem que enfrentar, especialmente em sua relação com as autoridades e com os homens comuns. As análises das peças procuram demonstrar como o comportamento destes personagens os fazem ser considerados heróis. Pelas dificuldades que cada um tem que passar, a sua personalidade é revelada e a sua escolha moral é o último passo em direção a esta revelação. A conduta do herói não tem repercussão individual mas coletiva. Isto acontece porque, mesmo que ele não perceba, o herói tem uma enorme influência sobre as pessoas que o admiram e o temem. $O$ papel da linguagem como um meio de manipular e legitimar o poder é discutido no último capítulo. Três aspectos deste uso arbitrário são analisados: a obrigação da confissão dos heróis, o uso de argumentação falaciosa pelas autoridades, e a autoridade de trabalhos escritos ou publicados. Em última análise o esforço do herói é para conservar sua integridade. De uma forma ou de outra ele também luta pelo bem do seu povo. Por outro lado, o principal objetivo das autoridades é eliminar qualquer tipo de oposição aos seus interesses. É fácil concluir que o conflito entre estas forças antagônicas não tem como ser evitado. É exatamente este conflito que os dramaturgos apresentam em suas peças. Todos eles acreditam no papel didático do teatro como um meio de transformar a sociedade. Através de seus heróis eles tentam resgatar os valores por eles incorporados em um mundo que está claramente necessitando deles. Ao mesmo tempo eles denunciam as práticas autoritárias que assaltam a liberdade individual de escolha e consciência. 
AUTORA: Meiri Estelito de Souza

ORIENTADORA: Profa. Dra. Iara Bemquerer Costa

INSTITUIÇĀO: Universidade Federal do Paraná

TÍTULO: "Análise de fatores de textualidade em redações escolares"

DATA DE DEFESA: 8 de março de 1999

BANCA EXAMINADORA: Profa. Dra. Iara Bemquerer Costa (UFPR)

Profa. Dra. Raquel Salek Fiad (UNICAMP)

Profa. Dra. Reny Maria Gregolin Guindaste (UFPR)

QUALIFICAÇÃO: Mestre

\section{RESUMO}

Partindo da concepção de que o texto tem um conjunto de características que o diferencia de uma sequiência de frases isoladas, descrevo sete fatores responsáveis pela textualidade: os fatores tipicamente pragmáticos (intencionalidade, aceitabilidade, informatividade, situacionalidade e intertextualidade), que são centrados nos participantes do discurso (produtor e receptor), de acordo com a proposta de Beaugrande \& Dressler (1986) e os fatores coerência e coesão a partir das quatro meta-regras de Charolles (1988), com a terminologia atualizada por Val (1997), ou seja, continuidade, progressão, não-contradição e articulação. Eu procuro avaliar o modelo dos sete fatores de textualidade a partir de infrações a cada um deles, visto que Beaugrande \& Dressler analisam tais fatores através da presença dos mesmos em textos literários conhecidos. Neste trabalho, as infrações são extraídas de 100 textos escritos por escolares, realizados durante uma avaliação do sistema educacional do Paraná em 1996. Por fim, eu analiso as infraçōes mais recorrentes na amostra a partir de uma redação prototípica, com o intuito de verificar as relações entre os fatores de textualidade. 
AUTORA: Elza de Fátima Dissenha Costa

ORIENTADORA: Profa. Dra. Regina Maria Przybycien

INSTITUIÇÃO: Universidade Federal do Paraná

TÍTULO: “Unspeakable things (un)spoken: the representation of black women in Toni Morrison's Beloved."

DATA DE DEFESA: 15 de março de 1999

BANCA EXAMINADORA: Profa. Dra. Regina Maria Przybycien (UFPR)

Profa. Dra. Susana Bornéo Funk (UFSC)

Profa. Dra. Mail Marques de Azevedo (UFPR)

QUALIFICAÇÃO: Mestre

\section{RESUMO}

Este trabalho consiste de uma investigação sobre a representação da mulher negra no romance Beloved, de Toni Morrison, do ponto de vista da mãe escrava. O principal objetivo foi o de demonstrar como Morrison busca na história, na memória, na magia e na imaginação meios de inverter noções ocidentais sobre o feminino e a maternidade e de criar novas possibilidades para essa representação.

A fim de demonstrar este ponto de vista, primeiro estudei a herança cultural e literária híbrida de Toni Morrison. Após, investiguei a relação entre a História e a Literatura, baseando-me principalmente no conceito de história como um entremeio entre o mundo real e o imaginário. Também analisei o Realismo Mágico e sua relação com a história de acordo com as idéias de Alejo Carpentier e Frederick Jameson. Em seguida, especulei sobre o narrar mágico-realista como um meio de aumentar a significância de um texto, como proposto por Scott Simpkins.

Meu próximo passo foi analisar as narrativas da escravidão tanto como documentos históricos quanto como trabalhos ficcionais e mostrar como a descrição do feminino nestas narrativas ajudou a formar uma imagem negativa da mulher negra. Em seguida, contei com a ajuda de algumas idéias de Bakhtin sobre as relações dialógicas que ocorrem dentro da linguagem e com seus conceitos de polifonia e discurso quase-direto como meio de iluminar algumas das estratégias narrativas empregadas por Morrison. Finalmente, todas estas idéias mostram que Morrison consegue resgatar a voz reprimida da mulher negra, tanto na literatura quanto na vida, com uma maestria singular. 
AUTORA: Maria Alice Maschio de Godoy

ORIENTADORA: Profa. Dra. Odete Pereira da Silva Menon

INSTITUIÇĀO: Universidade Federal do Paraná

TÍTULO: "A indeterminação do sujeito no interior paranaense: uma abordagem sociolinguística" DATA DE DEFESA: 23 de abril de 1999

BANCA EXAMINADORA: Profa. Dra. Odete Pereira da Silva Menon (UFPR)

Profa. Dra. Ângela Cecilia Rodrigues (USP)

QUALIFICAÇĀO: Mestre

Prof. Dr. Carlos Alberto Faraco (UFPR)

\section{RESUMO}

Este estudo variacionista tem por objetivo descrever o fenômeno da indeterminação do sujeito tal como se apresenta $\mathrm{em}$ uma amostra do português falado $\mathrm{em}$ Irati, Londrina e Pato Branco, cidades do interior paranaense pesquisadas pelo projeto VARSUL (Variação Lingüística Urbana na Região Sul do País). A Gramática Tradicional atribui o caráter de indeterminação a apenas dois tipos de sujeito: com o verbo (intransitivo ou transitivo indireto) na terceira pessoa do singular, acompanhado do pronome se; e com o verbo na terceira pessoa do plural, sem sujeito expresso. Entretanto, alguns trabalhos de abordagem gerativista, discursiva e variacionista apresentam diversos outros recursos por meio dos quais o sujeito indeterminado se realiza. Nosso trabalho, fundamentado em Menon (1994), apresenta como formas de indeterminação as variantes: a gente, eles, eu, FNs (formas nominais), nós, se, tu, você, VPSA (voz passiva sem agente), $\emptyset$ V3PS (verbo na terceira pessoa do singular), $\emptyset \mathrm{V} 3 P P$ (verbo na terceira pessoa do plural), distribuídas em 6.826 ocorrências, obtidas em 72 entrevistas, cada uma com aproximadamente 45 minutos de duração. Na análise desses dados, submetidos ao conjunto de programas estatísticos VARBRUL, levamos em consideração a variável linguiistica tempos e modos verbais e os fatores extralingüísticos sexo, faixa etária, escolaridade e localidade. Os resultados mostraram que, primeiramente, as formas apresentadas pela Gramática Tradicional não são as mais usadas no corpus; depois, que as formas você e $\emptyset V 3 P S$ de um modo geral são as mais empregadas, que o tempo presente do indicativo é o mais propício para a indeterminação e que os fatores extralingüísticos considerados exercem influência na escolha do recurso de que o falante se vale para indeterminar o sujeito em seus enunciados. 
AUTORA: Maria Helena Pires Santos

ORIENTADORA: Profa. Dra. Odete Pereira da Silva Menon

INSTITUIÇÃO: Universidade Federal do Paraná

TÍTULO: "Fatores de risco para o sucesso escolar de crianças brasiguaias nas escolas de Foz do Iguaçu: uma abordagem sociolingüística"

DATA DE DEFESA: 23 de julho de 1999

BANCA EXAMINADORA: Profa. Dra. Odete Pereira da Silva Menon (UFPR)

Profa. Dra. Stella Maris Bortoni-Ricardo (UNB)

Profa. Dra. Cecília Inês Ertal (UFPR)

QUALIFICAÇÃO: Mestre

\section{RESUMO}

$O$ foco deste trabalho foi investigar os fatores sociolingüisticos que compõem o conflito lingüístico entre o português (língua materna) e o espanhol (segunda língua) e mostrar como esses fatores interferem na aprendizagem dos alunos brasiguaios, no universo escolar público de Foz do Iguaçu, com a finalidade de apontar as diferenças e/ou semelhanças entre o desempenho escolar destes alunos e dos alunos brasileiros. Seis fatores se evidenciaram comprometedores, embora não se possa estabelecer uma gradação entre eles porque a influência de um sobre o outro é recíproca: 1 . A situação diglóssica conflitiva que recobre o processo histórico de formação do grupo brasiguaio e sua inserção no processo educacional; 2 . $\mathrm{O}$ bilingüismo a que estão expostos estes alunos; 3 . O processo educacional de submersão que parece ser comum na educação das minorias lingüísticas; 4 . As barreiras criadas pelas diferenças dialetais que dificultam o acesso ao dialeto de prestígio; 5 . As diferenças culturais que os identificam enquanto grupo e os diferenciam dos demais; 6 . As atitudes sociolingüísticas das instituições educacionais, dos pais, professores e dos próprios alunos que contribuem para a manutenção de um sentimento de inferioridade e consequiente fracasso escolar. Os pressupostos teóricos para a investigação dizem respeito às seis áreas que recobrem os fatores de risco: diglossia conflitiva, bilingüismo, bidialetalismo, processo educacional, diferenças culturais e atitudes sociolingüísticas. Os dados desta pesquisa foram obtidos através de entrevistas gravadas em fita cassete, conversas informais com professores, supervisores e alunos, xerox de textos e de cadernos de alunos brasiguaios e brasileiros, xerox de redações de alunos brasileiros da 8. ${ }^{a}$ série realizadas nas provas do Programa de Avaliação do Sistema Educacional do Paraná. Os resultados obtidos nos permitem dizer que os seis fatores sociolingüísticos exercem uma influência mais acentuada nos alunos brasiguaios das séries iniciais do $1 .^{\circ}$ grau, embora se torne difícil delimitar uma série em que as dificuldades se mostram com maior ou menor intensidade. Comparando alunos brasiguaios e brasileiros, constatamos que, salvo quanto ao bilingüismo português/espanhol vivenciado pelos brasiguaios, ambos estão sujeitos aos demais fatores de risco. 
AUTOR: Alexandre Sebastiāo Ferrari Soares

ORIENTADORA: Profa. Dra. Odete Pereira da Silva Menon

INSTITUIÇÃO: Universidade Federal do Paraná

TÍTULO: "Segunda e terceira pessoa - o pronome possessivo em questão: uma análise variacionista" DATA DE DEFESA: 23 de julho de 1999

BANCA EXAMINADORA: Profa. Dra. Odete Pereira da Silva Menon (UFPR)

Profa. Dra. Edair Maria Gorski (UFSC)

Profa. Dra. Iara Bemquerer Costa (UFPR)

QUALIFICAÇÃO: Mestre

\section{RESUMO}

Os pronomes possessivos de segunda e terceira pessoas nos são apresentados, na maioria das gramáticas normativas como se, quando do seu emprego, houvesse apenas uma única regularidade: teu e vosso para a segunda pessoa e seu para a terceira (e as respectivas flexões). Há regularidade quando do emprego desses pronomes na língua oral, porém bastante distinta da apresentada nas gramáticas normativas.

Neste trabalho procura-se descrever o funcionamento dos pronomes possessivos de segunda e terceira pessoas, verificando de que forma os fatores lingüísticos (posição do pronome possessivo no sintagma nominal, identificação do referente e o valor semântico do possessivo) e extralingüísticos (tais como idade, sexo, escolaridade e etnia) estariam condicionando o uso, na língua oral, dos pronomes em estudo, com base na observação do corpus do banco de dados do VARSUL em quatro cidades do Paraná: Curitiba, Irati, Londrina e Pato Branco. Apresenta-se, neste trabalho, o resultado da observação desses fatores em relação ao uso efetivo desses pronomes. As formas pronominais possessivas correspondentes à segunda pessoa são: teu, seu, de você e do senhor e para a terceira, seu e dele e as respectivas flexões, algumas mais favorecidas que outras pelos fatores lingüísticos e extralingüísticos observados neste corpus. Dentre os fatores mais significativos, temos então, para com os pronomes de segunda pessoa: com o possessivo teu, como ambientes favoráveis, aqueles em que os informantes eram da primeira faixa etária com formação correspondente ao segundo grau; seu ( $2^{\mathrm{a}}$ pessoa), no geral, foi mais utilizado pelos informantes da segunda faixa etária com formação correspondente ao primário; para com os pronomes de terceira pessoa: dele foi usado, no geral, com referentes determinados e específicos e teve o uso favorecido, entre outros fatores, na cidade colonizada por mineiros e paulistas; seu ( $3^{\mathrm{a}}$ pessoa) foi usado, de forma geral, com referentes indeterminados, no sintagma nominal a sua posição, quase que de maneira absoluta, foi anteposta ao substantivo. 
AUTOR: Altair Pivovar

ORIENTADOR: Prof. Dr. Carlos Alberto Faraco

INSTITUIÇÃO: Universidade Federal do Paraná

TÍTULO: "Leitura e escrita: a captura de um objeto de ensino"

DATA DE DEFESA: 30 de agosto de 1999

BANCA EXAMINADORA: Prof. Dr. Carlos Alberto Faraco (UFPR)

Profa. Dra. Roxane Helena Rodrigues Rojo (USP)

Profa. Dra. Iara Bemquerer Costa (UFPR)

QUALIFICAÇÃO: Mestre

\section{RESUMO}

Este trabalho se propõe a uma discussão teórica acerca dos problemas que afetam o ensino de língua portuguesa, em especial na sua modalidade escrita, apresentando proposta alternativa para encaminhamento de atividades com texto em sala de aula. No primeiro capítulo, são abordadas as razões por que as novas orientaçōes dos estudos lingüísticos no Brasil não se convertem em alterações substantivas nas práticas de ensino, as quais vêm acusando um déficit no que diz respeito à leitura e produção de textos pelos alunos. Procuramos mostrar de que forma o modelo científico de se relacionar com o conhecimento interfere negativamente no aproveitamento escolar e entender o novo papel do professor nesse processo. O segundo capítulo é dedicado à questão, fundamental para nós, da passagem da manipulação da teoria para a prática, discutindo-se o que chamamos de ciclo lingüístico. Procuramos demonstrar também que a forte influência do contexto concreto da sala de aula, tanto na leitura quanto na produção de textos, é subestimada pela escola. Ao terceiro capítulo reservamos a espinhosa tarefa de apresentar uma atividade escolar com texto elaborada dentro de princípios teóricos que dêem a garantia de que os alunos, de fato, vão interagir com enunciados de outros gêneros além do gênero específico (e inevitável) da escola, participando de uma real situação de aprendizagem da língua. 


\author{
AUTORA: Luciana Panke \\ ORIENTADORA: Profa. Dra. Iara Bemquerer Costa \\ INSTITUIÇĀO: Universidade Federal do Paraná \\ TÍTULO: "O papel da linguagem na argumentação. Um estudo de caso: José Eduardo de An- \\ drade Vieira, o banqueiro senador dos trabalhadores" \\ DATA DE DEFESA: $10^{\circ}$ de setembro de 1999 \\ BANCA EXAMINADORA: Profa. Dra. Iara Bemquerer Costa (UFPR) \\ Prof. Dr. Rafael Antônio Duarte Villa (UFPR) \\ Prof. Dr. Carlos Alberto Faraco (UFPR)
}

QUALIFICAÇĀO: Mestre

\title{
RESUMO
}

Este trabalho aplica a teoria da argumentação proposta por Chaim Perelman e Lucie Olbrechts-Tyteca aos discursos eleitorais de José Eduardo de Andrade Vieira, na campanha para o Senado Federal em 1990. Escolhemos este objeto de estudo para tentar averiguar como um empresário, na época presidente de um dos maiores bancos privados do país, conseguiu eleger-se senador como representante dos trabalhadores. Esta suposta contradição despertou o interesse acadêmico e questionamentos sobre qual o papel da linguagem no periodo eleitoral.

A metodologia utilizada neste estudo foi a pesquisa de campo e os recursos bibliográficos. Tendo como principal referência o Tratado da argumentação de Perelman e OlbrechtsTyteca aplicamos essa teoria aos programas eleitorais de Vieira, veiculados pela televisão no Horário Eleitoral Gratuito do Tribunal Regional Eleitoral.

Com esta pesquisa, pudemos constatar que a linguagem é um dos principais recursos na criação de imagens, podendo resultar na mudança de comportamento de uma comunidade. A campanha de Vieira construiu uma imagem que omitia, diversas vezes, as reais características do candidato. Isto fez com que ele se aproximasse do público-alvo de forma a provocar uma identificação com o mesmo através de outros aspectos ressaltados. O mais impressionante foi que a argumentação de Vieira baseou-se, praticamente, apenas na ligação entre a pessoa e seus atos. Isto significa que não houve uma preocupação em mostrar, de forma objetiva, as propostas eleitorais e, sim, em fazer com que a população confiasse em Vieira e se identificasse com ele. Os argumentos enfatizaram características pessoais que cram de interesse para a solidificação da imagem do candidato. 
AUTORA: Sozângela Schemim da Matta

ORIENTADORA: Profa. Dra. Reny Maria Gregolin Guindaste

INSTITUIÇĀO: Universidade Federal do Paraná

TÍTULO: "Um estudo sobre a compreensão de orações relativas com crianças em idade escolar"

DATA DE DEFESA: 2 de setembro de 1999

BANCA EXAMINADORA: Profa. Dra. Reny Maria Gregolin Guindaste (UFPR)

Prof. Dr. José Erasmo Gruginski (UFPR)

Prof. Dr. Antônio José Sandmann (UFPR)

QUALIFICAÇÃO: Mestre

\section{RESUMO}

A partir dos princípios da tcoria gerativa, este trabalho tem como objetivo analisar a competência lingüística de crianças consideradas "desviantes" do processo escolar, utilizando testes de compreensão de sentenças contendo orações relativas.

Através da experimentação, foram testadas sentenças, vistas como "objetos lingüísticos", em dois grupos de crianças de séries iniciais de uma escola integrada em um Projeto de Extensão multidisciplinar, o qual originou o inicial interesse que culminou nesta pesquisa.

Com base nos estudos de Sicuro Corrêa (1996), Grodzinsky (1989), Ouhalla (1991), Gregolin Guindaste (1996), entre outros, a análise dos dados foi direcionada em dois aspectos: primeiro, para verificar quais circunstâncias estruturais sāo mais fáceis e/ou mais difíceis aos sujeitos e quais os fatores que se revelam como interferentes na compreensão dessas estruturas; segundo, se há correspondência entre os testes psicológicos realizados no projeto e os testes lingüísticos de compreensão das sentenças desta dissertação.

- menor indice de acertos obtidos pelas crianças do Grupo do Projeto comparado ao desempenho do Grupo de Controle, cujo índice de acertos foi significativamente maior, apontam que a capacidade de compreensão dessas estruturas parece variar conforme uma certa capacidade cognitiva evidenciada pelo desempenho escolar. Estes testes lingüísticos de compreensão de orações relativas podem ainda ser comparados com os resultados dos testes psicológicos para validação de ambos os testes. 
AUTOR: Hugo Marcelo Fuzeti Abati

ORIENTADORA: Profa. Dra. Marta Morais da Costa

INSTITUIÇĀO: Universidade Federal do Paraná

TÍTULO: "Da lavoura arcaica: fortuna crítica, análise e interpretação da obra de Raduan Nassar" DATA DE DEFESA: 26 de outubro de 1999

BANCA EXAMINADORA: Profa. Dra. Marta Morais da Costa (UFPR)

Prof. Dr. Alcides Celso de Oliveira Villaça (UNICAMP)

QUALIFICAÇĀO: Mestre

Prof. Dr. Édison José da Costa (UFPR)

\section{RESUMO}

A dissertação Lavoura arcaica: fortuna crítica, análise e interpretação da obra de Raduan Nassar, reúne as informações críticas publicadas sobre a narrativa Lavoura arcaica, de Raduan Nassar, publicadas em jornais, revistas, cadernos especializados, no Brasil e no exterior, e em dissertações produzidas em universidades brasileiras. $O$ trabalho privilegia, além disso, a análise e interpretação de coordenadas semânticas da obra (enfoques discursivo, filosófico, poético, religioso, psicológico, moral, etc) e de estruturas formais (relativas a aspectos poéticos e literários). Acompanha a dissertação um histórico sobre Raduan Nassar, informações sobre seu processo de criação e outros textos de apoio à compreensão da obra. 
AUTOR: Rogério de Oliveira

ORIENTADORA: Profa. Dra. Elena Godoi

INSTITUIÇÃO: Universidade Federal do Paraná

TÍTULO: "Do progressivo do inglês ao progressivo do português"

DATA DE DEFESA: 18 de novembro de 1999

BANCA EXAMINADORA: Profa. Dra. Elena Godoi (UFPR)

Profa. Dra. Roberta Pires de Oliveira (UFSC)

QUALIFICAÇÃO: Mestre

Prof. Dr. Michel Gagnon (UFPR)

\section{RESUMO}

Este trabalho diz respeito à análise daquelas construções progressivas da língua inglesa - "verb+-ing" - que ocorrem juntamente com o verbo de ligação "to be", em suas várias formas, constituindo sintagmas verbais chamados de "Progressive Tenses", e sua(s) contrapartida(s) em português.

Para dar suporte a esta análise, foram arroladas algumas das principais teorias de tempo gramatical e aspecto dos lingüistas mais eminentes, bem como a teoria de representação do discurso (DRT) de Hans Kamp.

A "Teoria da Representação do Discurso" (DRT) é a teoria de que faz-se uso para formalizar a constituição temporal e aspectual do significado das sentenças na forma simples e progressiva do inglês. A mesma teoria de representação, após a modificação sugerida, deve ser capaz de representar as formas simples e progressivas do português. O objetivo último é sugerir uma proposta para a análise do progressivo do português. Mais precisamente, para a análise de construções como "estava verbo+-ndo" e "esteve verbo+-ndo". Após a investigação da diferença semântica entre essas duas perífrases, que não encontra par em língua inglesa, achou-se por bem reformular as estruturas de representação do discurso (DRSs), elaboradas por Kamp (1993) para a língua inglesa, para se expressar a diferença entre essas duas construções do português. 